NASA/TM-1998-206975

NI. 1

Adaptive Variable Bias Magnetic Bearing Control

Dexter Johnson and Gerald V. Brown

Lewis Research Center, Cleveland, Ohio

Daniel J. Inman

Virginia Polytechnic Institute and State University, Blacksburg, Virginia

Prepared for the

1998 American Controls Conference

sponsored by the American Automatic Control Council

Philadelphia, Pennsylvania, June 24-26, 1998

National Aeronautics and

Space Administration

Lewis Research Center 
Available from

NASA Center for Aerospace Information 7121 Standard Drive Hanover, MD 21076

Price Code: A03
National Technical Information Service 5287 Port Royal Road Springfield, VA 22100 Price Code: A03 


\title{
ADAPTIVE VARIABLE BIAS MAGNETIC BEARING CONTROL
}

\author{
Dexter Johnson and Gerald V. Brown \\ National Aeronautics and Space Administration \\ Lewis Research Center \\ Cleveland, Ohio 44135 \\ Daniel J. Inman \\ Virginia Polytechnic Institute and State University \\ Blacksburg, Virginia 24061
}

\begin{abstract}
Most magnetic bearing control schemes use a bias current with a superimposed control current to linearize the relationship between the control current and the force it delivers. With the existence of the bias current, even in no load conditions, there is always some power consumption. In aerospace applications, power consumption becomes an important concern. In response to this concern, an alternative magnetic bearing control method, called Adaptive Variable Bias Control (AVBC), has been developed and its performance examined. The AVBC operates primarily as a proportional-derivative controller with a relatively slow, bias current dependent, time-varying gain. The AVBC is shown to reduce electrical power loss, be nominally stable, and provide control performance similar to conventional bias control. Analytical, computer simulation, and experimental results are presented in this paper.
\end{abstract}

\section{INTRODUCTION}

Magnetic bearings are electromechanical devices that use magnetic forces to completely levitate a rotor without physical contact. The forces they produce depend nonlinearly upon the current flowing in the magnet coils and the distance between the rotor and the stator poles. In conventional operation of a magnetic bearing, a method known as the bias method is used to linearize the relationship between the current supplied to and the force delivered by the bearing. These devices cannot operate without closed loop electronic control because they are open loop unstable due to its attractiveonly nature. Usually classical control techniques such as proportionalderivative (PD) or proportional-integral-derivative (PID) feedback control are used.

For many space applications, conservation of power is a high priority issue. The research presented here focuses on the development, application, and effectiveness of Adaptive Variable Bias Control (AVBC) to reduce the power required to operate a magnetic bearing, consequently resulting in power-saving, while preserving stability and actuator frequency response. Reduced bias operation of magnetic bearings would not only provide electrical power-saving but would provide many other synergistic benefits, such as reduced power requirements, reduced heat transfer problems, and reduced rotor heating due to eddy currents and hysterises. This method is not purported to be a new method for rotordynamic control but rather a modification to the operating mode of a magnetic bearing to make it a more efficient control actuator. Analytical, simulation, and experimental results are presented.

Low or no bias research has been done by the primary author as part of his Ph.D. dissertation (see Johnson, 1995), involving zero bias and pseudo-zero bias control. Zero bias work has also been done by Brown and Grodsinsky, 1991, Ishida, 1990, and Johnson, et al.,
1991. Some early work was done by Cunningham, et al., 1978, and Sperry Flight Systems, 1979, that involved limited real-time bias adjustment. Extensive analysis of power loss (hysterises, eddy current, windage, configuration, etc.) in magnetic bearing systems has been done by Kasarda, et al., 1997. Recent work reported involves an advanced control method applied to low bias systems (Knospe and Yang, 1997).

\section{ACTIVE MAGNETIC BEARING OPERATION Magnetic Bearing Force Equations}

A typical magnetic bearing comprises a set of radially positioned electromagnets positioned in opposing pairs around a laminated magnetic bearing journal (See Fig. 1). For a magnetic bearing with four electromagnets there is one opposing pair for each perpendicular axis. Each electromagnet consists of a laminated core and one or more coil windings. In the experimental configuration used in this research the poles are uniformly positioned 45 degrees apart (See Fig. 2).

The force produced by a single two pole electromagnet can be shown to be given by the following equation where $I$ is the total current in the magnet coils, $X_{g}$ is the gap distance, $\mu_{0}$ is the permeability of free space, $A$ is the pole face area, and $N$ is the number of coil turns:

$$
F=-\frac{\mu_{0} A N^{2}}{4} \frac{I^{2}}{X_{g}^{2}}
$$

The force in Eq. (1) is attractive and increases as the gap decreases. This attractive force produces an unstable system for an open loop magnetic bearing configuration. The net force, $F_{n}$, produced by an opposing pair of identical two-pole electromagnets on a single axis is the sum of the forces produced by each electromagnet; taking account of the sign convention (see Fig. 1), the net force equation is given as follows:

$$
F_{n}=\frac{\mu_{0} A N^{2}}{4}\left[\frac{\left(I_{1}\right)^{2}}{\left(X_{g 1}\right)^{2}}-\frac{\left(I_{2}\right)^{2}}{\left(X_{g 2}\right)^{2}}\right]=Z\left[\frac{\left(I_{1}\right)^{2}}{\left(X_{g 1}\right)^{2}}-\frac{\left(I_{2}\right)^{2}}{\left(X_{g 2}\right)^{2}}\right]
$$

$l_{j}$ is the current in magnet $j$, and $X_{g j}$ is the gap distance for magnet $j$. Previously, the equations were given for the static force produced by a magnetic bearing along a single axis. That force is affected dynamically by the rate limit at which current changes in the coils, called the current slew rate limit, which is dependent on the voltage limit, $V_{\max }$, of the power supply and the coil inductance, $L$. An approximate expression for the slew rate limit is equal to $V_{\max } / L$. 


\section{Conventional Bias Current Operation}

Conventional magnetic bearing practice linearizes the forcecurrent relationship by using a bias current along with a superimposed control current. In order to obtain a linear relation between force and control current we express the currents $I_{1}$ and $I_{2}$ in the opposing coils as:

$$
\begin{aligned}
& I_{1}=I_{b}+I_{c} \\
& I_{2}=I_{b}-I_{c}
\end{aligned}
$$

where $I_{b}$ is the bias current and $I_{c}$ is the perturbation or control current. Next we express each gap in terms of the nominal gap $X_{0}$ and the deviation $X$ from this nominal value caused by rotor displacement:

$$
\begin{aligned}
& X_{g 1}=X_{0}-X \\
& X_{g 2}=X_{0}+X
\end{aligned}
$$

Combining Eqs. (2) to (4) yields:

$$
F_{x}=Z\left[\frac{\left(I_{b}+I_{c}^{2}\right)}{\left(X_{0}-X\right)^{2}}-\frac{\left(I_{b}-I_{c}^{2}\right)}{\left(X_{0}+X\right)^{2}}\right]
$$

A linear relationship between force and control current and position can be obtained by assuming $X \ll X_{0}$ and $I_{c} \ll I_{b}$, which can be shown to result in the following equation:

$$
F_{n}=\frac{4 Z I_{b}^{2}}{x_{0}^{3}} X+\frac{4 Z I_{b}}{X_{0}^{2}} I_{c}=K_{x} X+K_{i} I_{c}
$$

$K_{x}$ is the bias (negative) stiffness and $K_{i}$ is the current stiffness.

This linearized force equation is generally used for linear control development even though the assumptions that were made are frequently violated in practice. For proportional-derivative feedback control the following relation is used.

$$
I_{c}=-\left(K_{p} X+K_{d} \dot{X}\right)
$$

where $K_{p}$ is the proportional control gain and $K_{d}$ is the derivative control gain.

\section{ADAPTIVE VARIABLE BIAS CONTROL Preliminary Control Design}

To simplify the equations describing the controls, the important variables will be transformed into nondimensional variables. The nondimensional factors will be used for both AVBC and conventional bias control methods but are derived from parameters and variables that are predominantly associated with the bias method. They are also based on the force and power electronic equations presented earlier.
In the defining equations below, capitalized variables are dimensional and the lower case variables generally are nondimensional. Additionally, subscripts 1 and 2 refer to the right and left magnets, respectively.

$$
I_{b}=I_{\text {ref }}=\frac{I_{\max }}{2}, i=\frac{I}{I_{\text {ref }}}, i_{c}=\frac{I_{c}}{I_{\text {ref }}}, i_{b}=\frac{I_{b}}{I_{\text {ref }}}=1, v=\frac{V}{V_{\max }}
$$

$I_{\text {ref }}$ is the reference, or nondimensionalizing, current, $I_{\max }$ is the maximum allowable coil current, and $V_{\max }$ is the maximum power supply voltage.

We define a bias critical frequency, $\Omega_{c r}$ as the frequency at which voltage saturation first occurs for the conventional bias method with the bias current equal to the reference current:

$$
\Omega_{c r}=\frac{V_{\max }}{L_{r e f}}
$$

The frequency ratio is defined as follows, where $\Omega$ is the command frequency:

$$
\omega=\frac{\Omega}{\Omega_{c r}}
$$

The nondimensional time, $\tau$, whose units are cycles, is given as follows:

$$
\tau=\Omega t
$$

The instantaneous power, $P_{i}$, is defined as follows:

$$
P_{i}=I^{2} R
$$

The total energy, $E_{t}$, is defined as follows:

$$
E_{t}=\int_{0}^{\Omega_{r a d} T} I^{2} R d \Omega_{r a d} t
$$

$T$ is the period the total energy is being evaluated over and the subscript rad denotes radians.

The total nondimensional, $e_{t}$, energy is defined as follows:

$$
e_{t}=\frac{P_{t}}{I_{r e f}^{2} R}=\int_{0}^{\Omega_{r a d} T} i^{2} R d \Omega_{r a d}
$$

The average nondimensional power (total energy per cycle), $\bar{p}_{t}$ will be defined by the next equation. This variable will be used to evaluate the power used by each method.

$$
\bar{p}_{t}=\frac{e_{t}}{\omega T}
$$




\section{Conventional Bias (CB)}

The conventional bias method produces a linear operating actuator which enables use of many linear control techniques. The means by which this is accomplished was outlined earlier. The bias current is set to one-half the designed maximum allowable current to ensure that the control current never exceeds the bias current. If the command current magnitude exceeds the bias current, linearity remains intact but, due to the attractive-only behavior of each magnet, the resultant force would be counteractive to the desired actuation action. The bias current is responsible for the major portion of power dissipated when operating the actuator using this method. The nondimensional bias force, $f_{c b}$, is:

$$
f_{c b}=\frac{F x_{0}^{2}}{Z I_{\text {ref }}^{2}}=4 i_{c}
$$

\section{Adaptive Variable Bias Control (AVBC)}

A new proposed operating method for magnetic bearings is the Adaptive Variable Bias Control method (AVBC), based on the Conventional Bias (CB) method. The primary idea behind this control method is that by varying the bias current adaptively as needed, the power requirement can be reduced while producing the desired force and maintaining the linearization afforded by using bias. The main static influence in changing the bias current is to change the bearing static stiffness. Dynamically, there are two effects: the control laws depend on bias, and as the bias changes, the force slew rate limit changes. Since there are so many possibilities as to how to effectively vary the bias, the use of adaptive control is introduced. Adaptive control entails monitoring the operation of the magnetic bearing and determining from that information the best setting for the bias current for those conditions. Adaptive variable bias appears to be efficient and flexible enough to consider for a variety of magnetic bearing applications. The application of adaptive control here is a loose application of the self-tuning type of nonlinear adaptive controller. Here the bias current is a system parameter that can be changed by using information about how the system is operating. The "estimation" of the bias is not based on typical parameter estimation but it is determined by an online estimate based on the commanded current. We require that the bias must be equal to the amplitude of the command current. Thus, a simple adaptation law is obtained in that we find an average command current amplitude over some time span and set the bias equal to this average.

The operating control law can best be described as follows:

$$
i_{1}=\left|i_{c}\right|+i_{c}, i_{2}=\left|i_{c}\right|-i_{c}
$$

and the resulting nondimensional adaptive variable bias force, $f_{a v b}$, is:

$$
f_{a v b}=4\left|i_{c}\right| i_{c}
$$

\section{EXPERIMENTAL SET-UP}

In order to demonstrate the AVBC method on an actual physical system, experiments were performed. The set-up of the experimental magnetic bearing system is comprised of several interconnected electrical and mechanical components: a magnetic bearing, the power amplifiers, an IBM PC AT compatible computer, the $\mathrm{A} / \mathrm{D}$ and D/A boards, and a Rotor Kit. The Rotor Kit, which is manufactured by the Bently Nevada Corporation, is a precision model of a high-speed rotating machine that is designed for laboratory demonstration of radial shaft vibration. It can operate at speeds up to $12000 \mathrm{rpm}$. Its general use is for demonstrating experimental rotor dynamic phenomena but it is being used here with magnetic bearings to demonstrate the control methods presented in this work. The magnetic bearing is installed on the rotor kit at the end of the rotor away from the motor. The magnetic bearing is an 8-pole magnetic bearing (see Fig. 3) and was fabricated at the NASA Lewis Research Center. The design specifications are given in Fig. 2 . The force output of the magnetic bearing was characterized by the single force parameter, $Z$, determined experimentally to be approximately $5.76 \mathrm{e}-4 \mathrm{lbf}$-(in./A) ${ }^{2}$ which will be the $Z$ value used when calculating force from experimental current. Important parameters are listed in Table 1.

\section{RESULTS \\ Conventional Bias}

The conventional bias method is governed by the equations developed earlier. The simulations were run at four different force command levels with the command frequency equal to the bias critical frequency (frequency at which saturation occurs for peak force equaling maximum force output) of $80 \mathrm{~Hz}$. Figure 4 is a plot of several cycles of the resulting nondimensional currents due to various desired nondimensional forces for each electromagnet of the horizontal axis. For the current with the largest amplitude (dotted line) there is a noticeable linear portion as the positive peak amplitude is approached. This linear portion is due to voltage saturation. In Fig. 5, a plot of the force produced and the command current based on the commanded force is shown. A comparison of the command current in Fig. 5 and the resultant currents in Fig. 4 show that the desired output is achieved unless voltage saturation occurs; then the output is less than desired. The comparison of the output force and command current show that they are only different by a constant factor. Voltage saturation occurs only for the force with amplitude 4. These simulation results are virtually the same as those expected from the analytical description.

The experimental results for CB operation, with $2 \mathrm{~A}$ bias current and a particular command amplitude at the bias critical frequency of $80 \mathrm{~Hz}$, is shown in Fig. 6. Figure 7 shows the current, calculated force, and measured force for the bearing operating at low amplitude and frequency force command. This verifies the force producing ability under $\mathrm{CB}$ operation of the bearing with respect to analytical prediction.

\section{Adaptive Variable Bias}

The Adaptive Variable Bias Control (AVBC) method is governed by the equations developed earlier. The simulation of the AVBC method was run at the same four force commands as with the conventional bias. In Fig. 8 is a plot of several cycles of the resulting nondimensional currents for these four cases. Note that the form of the currents changes differently with commanded force than for the CB method (see Fig. 4). Also notice that the dc component of the current is approximately equal to the amplitude of the ac component. Hence for every force amplitude the minimum value of the currents is always near zero. Additionally, as with conventional bias for $f=4$, there is an appearance of linear form due to voltage saturation. In Fig. 9 a plot of the force produced and the command current based on the commanded force is shown. A comparison of the command current in Fig. 9 and the resultant currents in Fig. 8 show that, 
in general, the desired output is achieved; but if voltage saturation occurs the output is less than desired. The comparison of the output force and command current show that they are only different by a constant factor, except when voltage saturation significantly affects the force at an amplitude of 4 . The simulation results yielded the variable bias operational characteristics as expected from the analytical description.

The experimental results for AVBC operation are shown in Figs. 10 to 12. Figure 10 shows the resulting current for a particular command amplitude at the bias critical frequency of $80 \mathrm{~Hz}$. Figure 11 shows the current, calculated force, and measured force for the bearing operating at low amplitude and frequency force command. This verifies that the force produced under AVBC operation matches the analytical prediction. Figure 12 shows how this method changes the bias current according to the control current, indicating very stable adaptation features.

\section{Force and Power Consumption Evaluation}

In Fig. 13, there are plots of analytical, experimental and simulated power versus force data for the AVBC and the CB method. For the CB method, the data reveals a parabolic relationship between force and power with a nonzero power value at zero force, attributed to the ever-present bias current. The analytical solution matches well with simulation data. The simulation data point that is farthest to the right is off from the analytical results because the simulation includes the resistive effects in the current dynamics which adds to the voltage causing voltage saturation earlier than for inductive voltage only and for high current values it becomes more influential. The experimental results match the other results well. For the AVBC method, there is a linear relationship between force and power with a zero power value at zero force. The analytical solution matches well with simulation data, except for the point mentioned before. The experimental results again match the other results well.

\section{DISCUSSION}

The results of the analysis of the Adaptive Variable Bias Control (AVBC) data has been presented. The analytical results were based on linearized equations, the simulation results were based on nonlinear equations, and the experimental results were from realtime, physical results. These results indicate how a magnetic bearing operates using the AVBC method. The Conventional Bias (CB) and AVBC methods produced the commanded force for the majority of the range of force commanded. For high force command there was some voltage saturation for simulated and experimental results for these bias-based methods. The effectiveness of the AVBC method to operate with minimal power was very good, in general, compared to the CB method. The CB method does not do well for low force levels due to the invariable bias current. As the commanded force level increases the difference in power dissipation between each method begins to decrease. For $f>3.5$, the CB and AVBC methods have comparable power levels. The results presented in this work shows that the AVBC has performed just as well as the CB method in producing force and is significantly better in using less power.

\section{CONCLUSION}

In conclusion, this research effort provided an analysis of AVBC, with a focus on operating with minimal power, and showed that it worked. This method was compared to the conventional operating method and it was determined to be viable. Further development can be performed by considering other adaptation schemes. The AVBC method proved to be a method of choice for power saving operation.

\section{REFERENCES}

Brown, G.V., Grodsinsky, C.M., "Magnetic Bearings with Zero Bias," Proceedings of Conference on Aerospace Applications of Magnetic Suspension Technology, NASA CP-10066, March, 1991, pp. 165-182.

Cunningham, D.C., Gismondi, T.P., Wilson, W., "System Design of the Annular Suspension and Pointing System (APS)," American Institute of Aeronautics and Astronautics International Aerospace Abstracts, 1978, Contract No. NAS-14214 (AIAA 78-1311), pp. 471-489.

Groom, N.J., Miller, J.B., "A Microprocessor-Based Table Lookup Approach for Magnetic Bearing Linearization," NASA TP-1838, May, 1981.

Ishida, S., "Linear Compensation for Magnetic Bearings," Second International Symposium on Magnetic Bearings, July 12-14, 1990 , pp. 311-318.

Johnson, D., Brown, G.V., Inman, D.J., "Force Analysis of Magnetic Bearings with Power-Saving Controls," Proceedings of the International Symposium on Magnetic Suspension Technology, NASA Conference Publication 3152, Part 2, August 19-23, 1991, pp. 595-613.

Johnson, D, "Alternative Operating Modes for Magnetic Bearing Control," Ph.D. dissertation, Mechanical and Aerospace Engineering Department, State University of New York at Buffalo, April, 1995.

Kasarda, M., Allaire, P.E., Norris, P.M., Maslen, E.H., Mastrangelo, C., "Comparison of Measured Rotor Power Losses in Homopolar and Heteropolar Magnetic Bearings," Proceedings of MAG '97 Industrial Conference abd Exhibition on Magnetic Bearings, August, 1997, pp. 323-333.

Knospe, C., Yang, C., "Control of Magnetic Bearing with Low Bias Flux," Proceedings of MAG '97 Industrial Conference and Exhibition on Magnetic Bearings, August, 1997, pp. 241-250.

Sperry Flight Systems, "Magnetic Suspension System for an Annular Momentum Control Device (AMCD)," NASA CR-159255, Contract No. NAS1-14502, December, 1979.

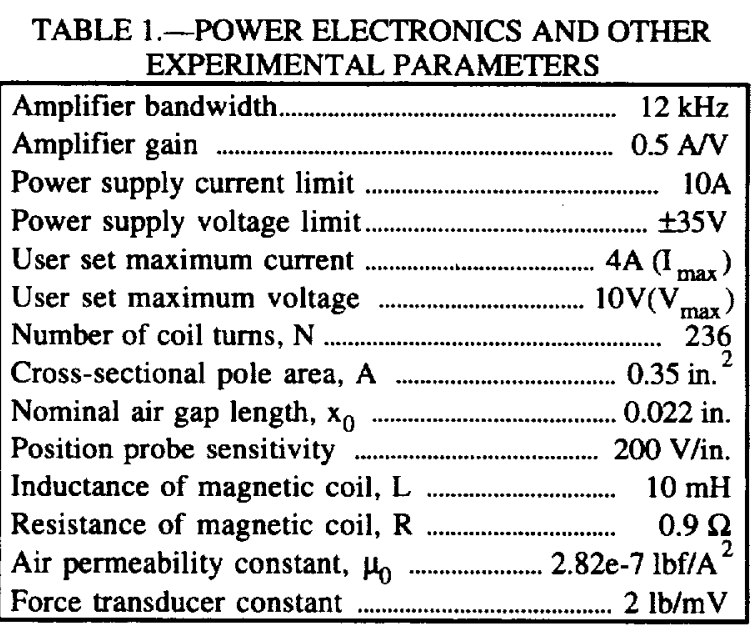




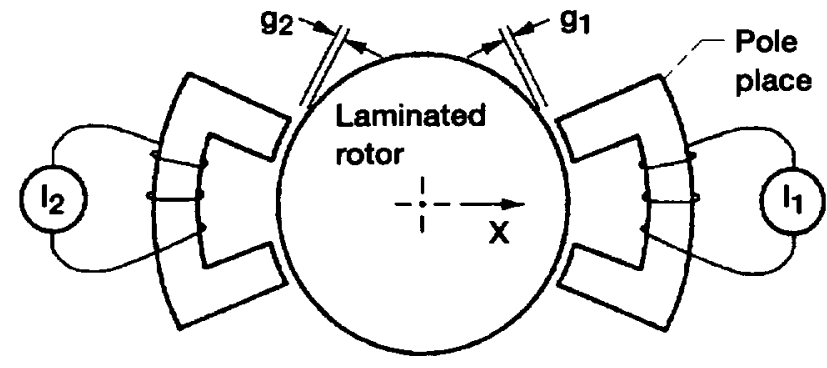

Figure 1.-Typical magnetic bearing configuration showing electromagnets only on one axis.
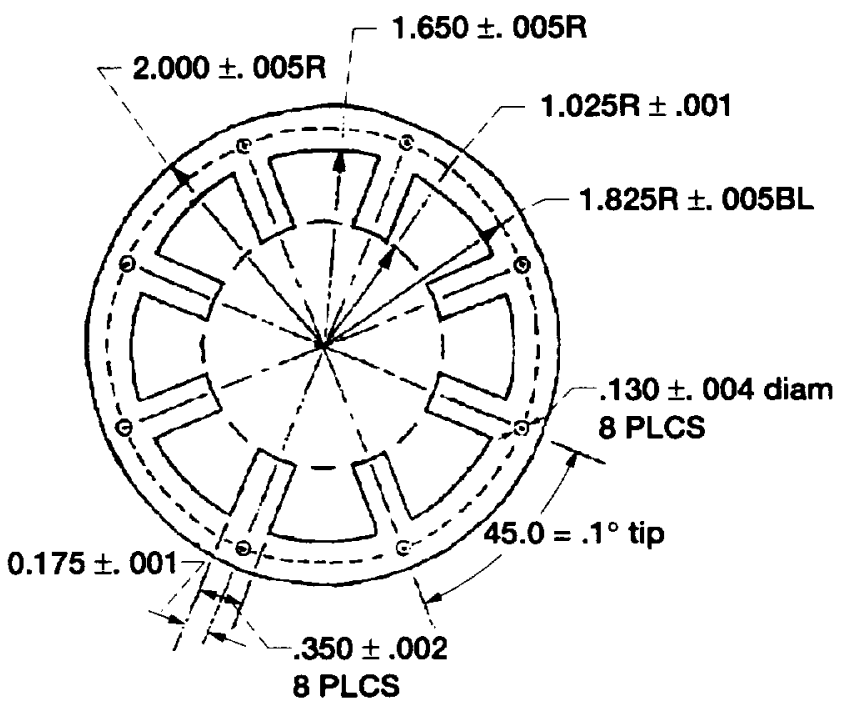

Figure 2.-Experimental configuration of an eight pole magnetic bearing.

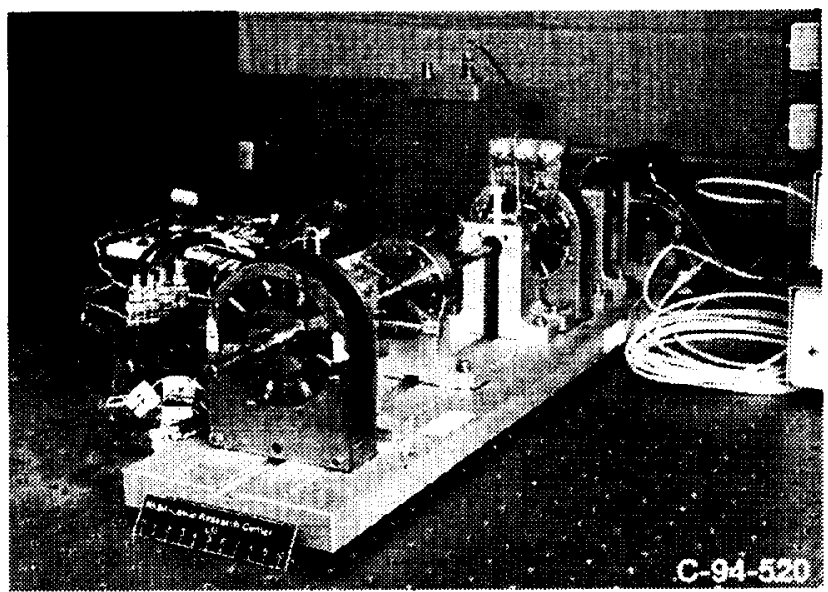

Figure 3.-Eight-Pole Radial Magnetic Bearing implemented in Bentley-Nevada Rotor Kit in Magnetic Bearing Research Lab at NASA Lewis Research Center in Cleveland, Ohio.
Nondimensional force command amplitude
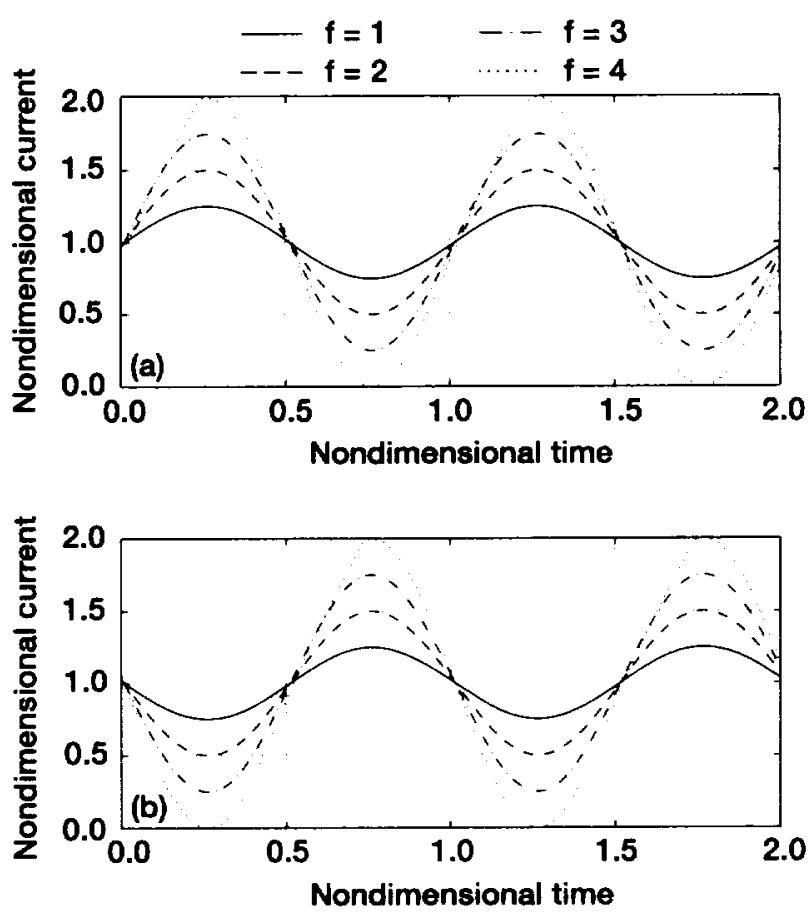

Figure 4.-Nondimensional output current for bias method simulation. (a) Right magnet. (b) Left magnet.

Nondimensional force command amplitude
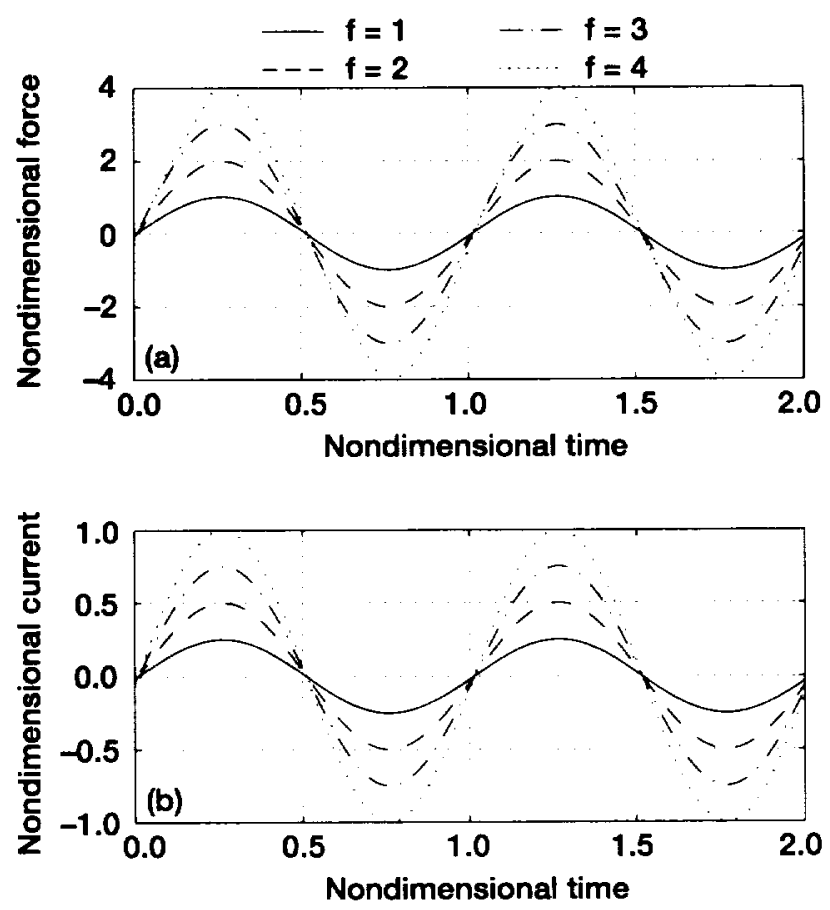

Figure 5.-Bias method simulation. (a) Nondimensional output force. (b) Command current. 


\section{Results}
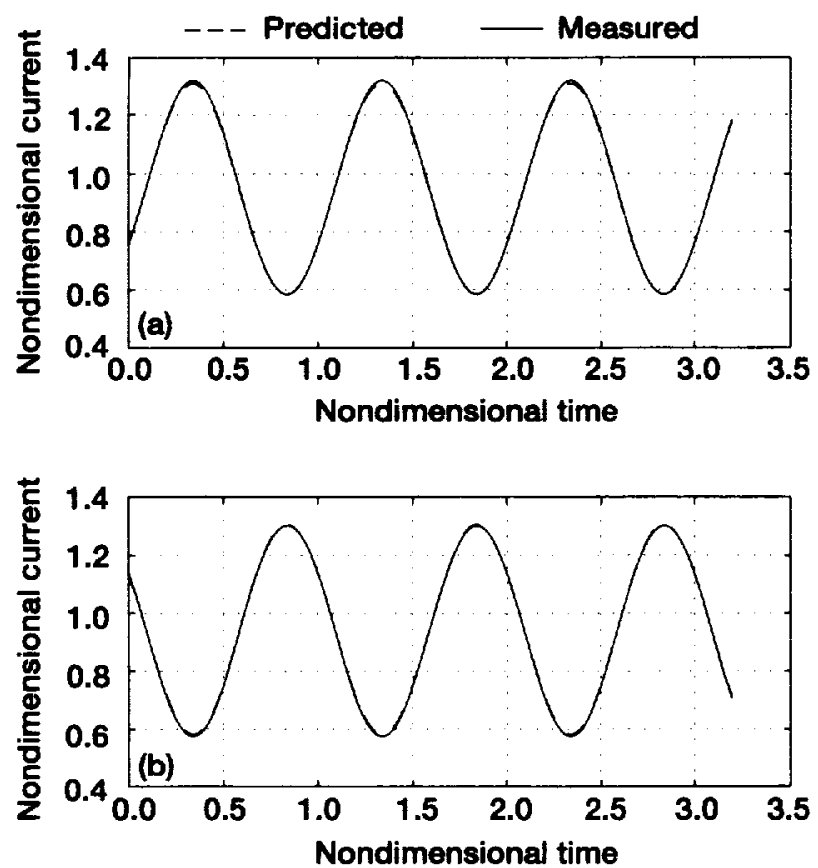

Figure 6. - Conventional bias experimental nondimensional current for command current $i_{c}=.375$. (a) Right magnet. (b) Left magnet.
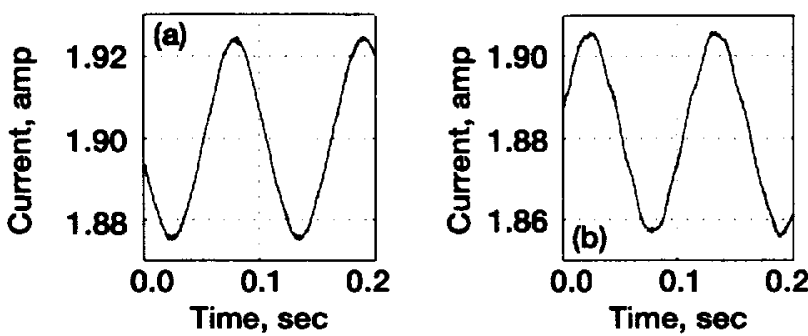

Force

- - Predicted
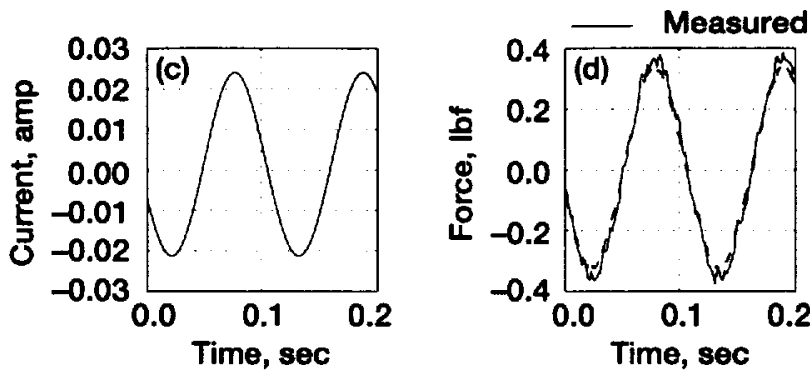

Figure 7.-Conventional bias experimental dimensional results for command current $I_{c}=0.0227$ amps and $\Omega=8.9 \mathrm{~Hz}$. (a) Right magnet. (b) Left magnet.

(c) Command current. (d) Measured and predicted force.
Nondimensional force command amplitude
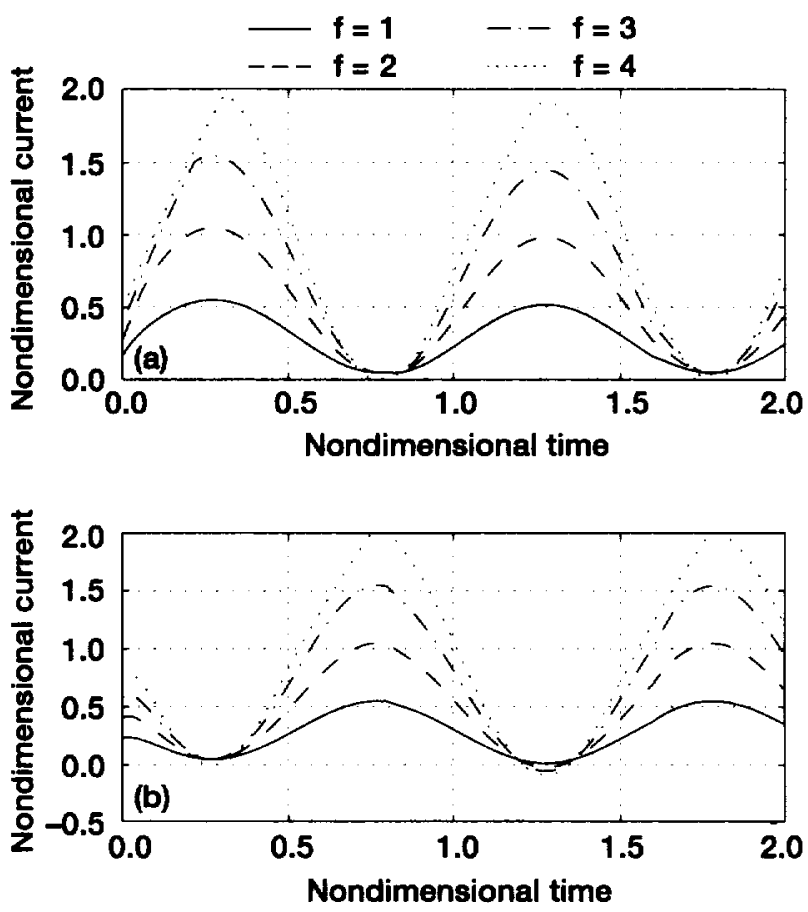

Figure 8.-Nondimensional output current for adaptive variable bias method simulation. (a) Right magnet.

(b) Left magnet.

Nondimensional force command amplitude
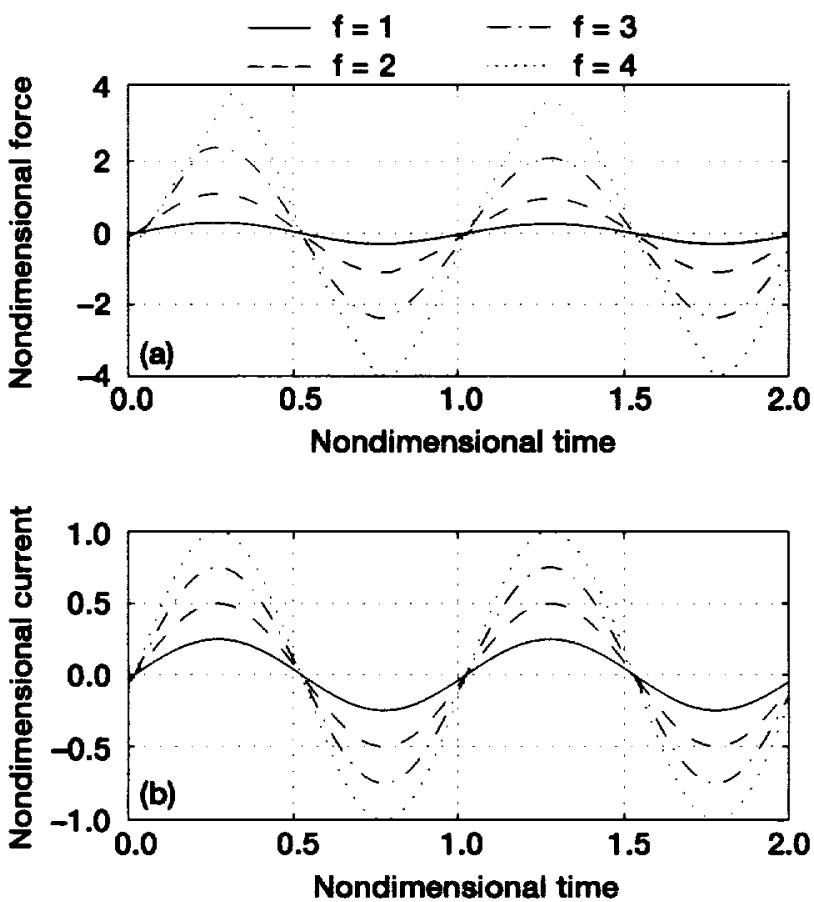

Figure 9.-Adaptive variable bias method simulation. (a) Nondimensional output force. (b) Command current. 
Results
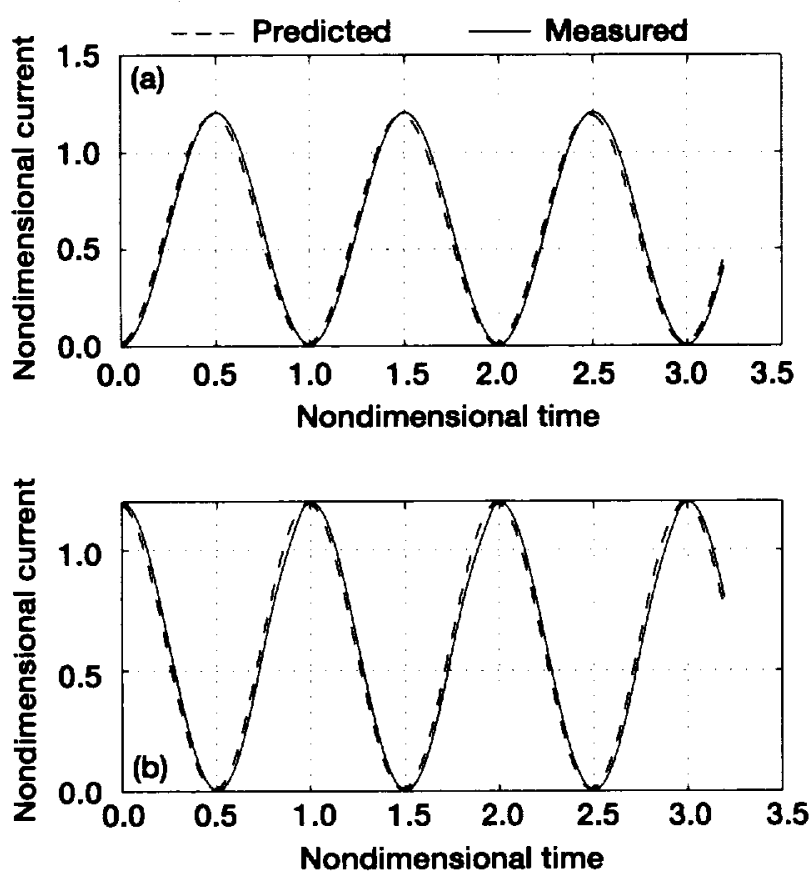

Figure 10.-Adaptive variable bias experimental nondimensional current for command current $i_{c}=.375$.

(a) Right magnet. (b) Left magnet.
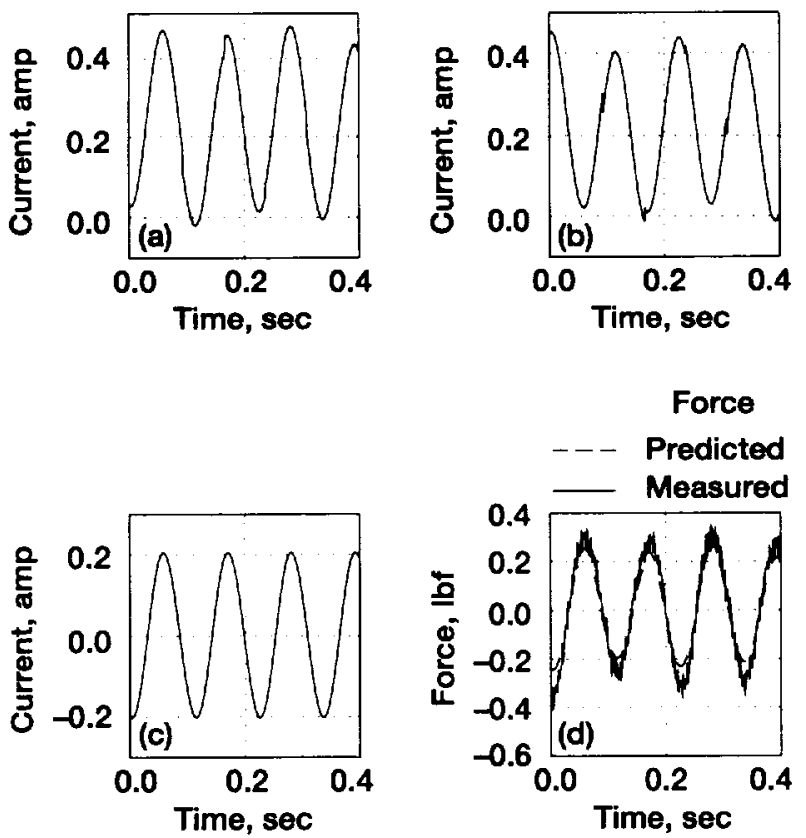

Figure 11.-Adaptive variable bias experimental dimensional results for command current $I_{c}=0.203$ amps and $\boldsymbol{\Omega}=\mathbf{8 . 9} \mathrm{Hz}$. (a) Right magnet. (b) Left magnet. (c) Command current. (d) Measured and predicted force.
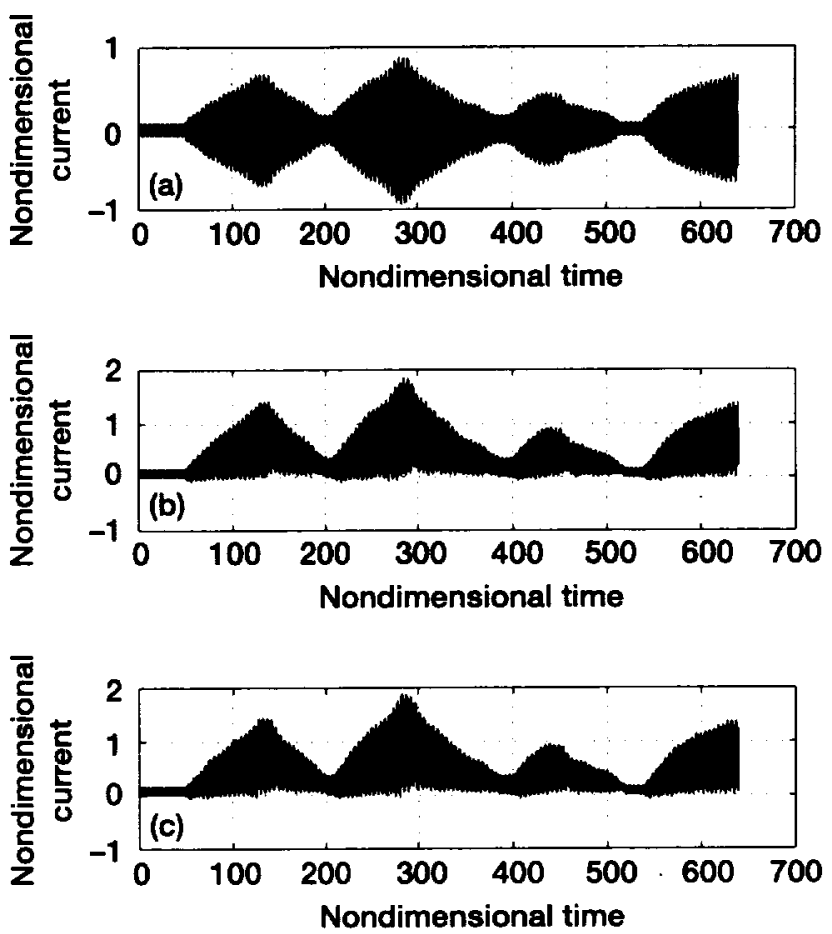

Figure 12. -Adaptive variable bias experimental currents. (a) Nondimensional command current. (b) Right magnet control current. (c) Left magnet control current showing adaptive characteristics.

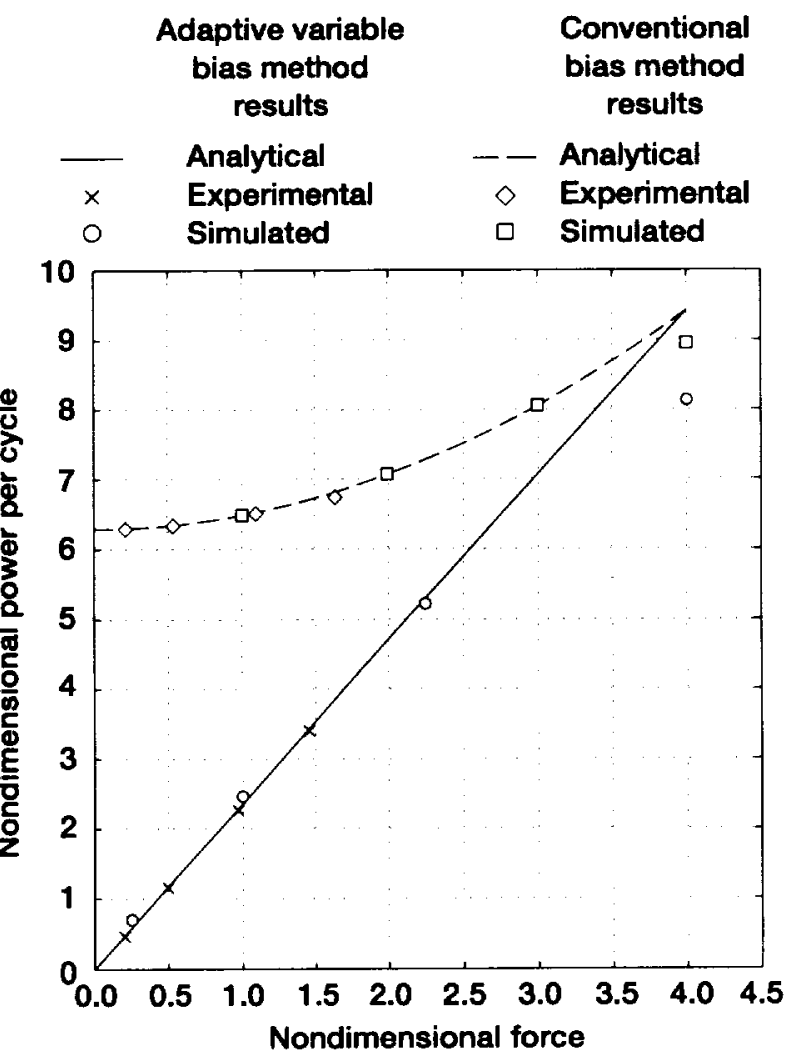

Figure 13.-Nondimensional power per cycle versus nondimensional force for the conventional bias method and adaptive variable bias method with $\omega=1$. 


\begin{tabular}{|c|c|c|c|c|}
\hline \multicolumn{3}{|c|}{ REPORT DOCUMENTATION PAGE } & \multicolumn{2}{|r|}{$\begin{array}{l}\text { Form Approved } \\
\text { OMB No. 0704-0188 }\end{array}$} \\
\hline \multicolumn{5}{|c|}{ 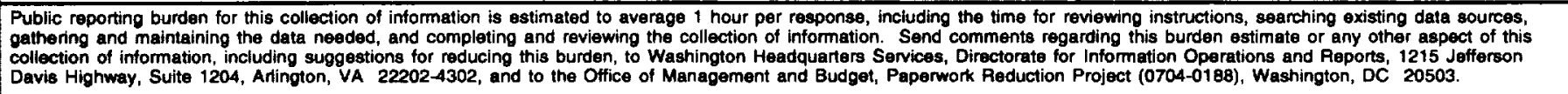 } \\
\hline 1. AGENCY USE ONLY (Leave blank) & $\begin{array}{r}\text { 2. REPOFT DATE } \\
\text { April } 1998\end{array}$ & \multicolumn{3}{|c|}{$\begin{array}{l}\text { 3. REPORT TYPE AND DATES COVERED } \\
\text { Technical Memorandum }\end{array}$} \\
\hline \multicolumn{3}{|c|}{$\begin{array}{l}\text { 4. TITLE AND SUBTITLE } \\
\text { Adaptive Variable Bias Magnetic Bearing Control }\end{array}$} & \multirow{2}{*}{\multicolumn{2}{|c|}{$\begin{array}{l}\text { 5. FUNDING NUMBERS } \\
\text { WU-523-22-13-00 }\end{array}$}} \\
\hline \multicolumn{3}{|c|}{$\begin{array}{l}\text { 6. AUTHOR(S) } \\
\text { Dexter Johnson, Gerald V. Brown, and Daniel J. Inman }\end{array}$} & & \\
\hline \multicolumn{3}{|c|}{$\begin{array}{l}\text { 7. PERFORMING ORGANIZATION NAME(S) AND ADDAESS(ES) } \\
\text { National Aeronautics and Space Administration } \\
\text { Lewis Research Center } \\
\text { Cleveland, Ohio } 44135-3191\end{array}$} & \multicolumn{2}{|c|}{$\begin{array}{l}\text { 8. PERFORMING ORGANIZATION } \\
\text { REPORT NUMBER } \\
\text { E-11127 }\end{array}$} \\
\hline \multicolumn{3}{|c|}{$\begin{array}{l}\text { 9. SPONSORING/MONITORING AGENCY NAME(S) AND ADDRESS(ES) } \\
\text { National Aeronautics and Space Administration } \\
\text { Washington, DC 20546-0001 }\end{array}$} & \multicolumn{2}{|c|}{$\begin{array}{l}\text { 10. SPONSORING/MONITORING } \\
\text { AGENCY REPORT NUMBER } \\
\text { NASA TM-1998-206975 }\end{array}$} \\
\hline \multicolumn{5}{|l|}{ 11. SUPPLEMENTARY NOTES } \\
\hline \multicolumn{5}{|c|}{$\begin{array}{l}\text { Prepared for the } 1998 \text { American Controls Conference sponsored by the American Automatic Control Council, Philadelphia } \\
\text { Pennsylvania, June 24-26, 1998. Dexter Johnson and Gerald V. Brown, NASA Lewis Research Center; Daniel J. Inman, } \\
\text { Virginia Polytechnic Institute and State University, Blacksburg, Virginia 24061. Responsible person, Dexter Johnson, } \\
\text { organization code } 5930,(216) 433-6046 .\end{array}$} \\
\hline \multicolumn{3}{|c|}{$\begin{array}{l}\text { 12a. DISTRIBUTIONAVAILABILITY STATEMENT } \\
\text { Unclassified - Unlimited } \\
\text { Subject Categories: } 37,31 \text {, and } 01 \quad \text { Distribution: Nonstandard } \\
\text { This publication is available from the NASA Center for AeroSpace Information, (301) 621-0390. }\end{array}$} & \multicolumn{2}{|c|}{ 12b. DISTRIBUTION CODE } \\
\hline \multicolumn{5}{|c|}{$\begin{array}{l}\text { Most magnetic bearing control schemes use a bias current with a superimposed control current to linearize the relationship } \\
\text { between the control current and the force it delivers. With the existence of the bias current, even in no load conditions, } \\
\text { there is always some power consumption. In aerospace applications, power consumption becomes an important concern. } \\
\text { In response to this concern, an alternative magnetic bearing control method, called Adaptive Variable Bias Control } \\
\text { (AVBC), has been developed and its performance examined. The AVBC operates primarily as a proportional-derivative } \\
\text { controller with a relatively slow, bias current dependent, time-varying gain. The AVBC is shown to reduce electrical power } \\
\text { loss, be nominally stable, and provide control performance similar to conventional bias control. Analytical, computer } \\
\text { simulation, and experimental results are presented in this paper. }\end{array}$} \\
\hline \multirow{3}{*}{\multicolumn{3}{|c|}{$\begin{array}{l}\text { 14. SUBJECT TERMS } \\
\text { Magnetic suspension; Magnetic bearing; Adaptive control; Controls }\end{array}$}} & & 15. NUMBER OF PAGES \\
\hline & & & & \begin{tabular}{|c|}
13 \\
16. PRICE CODE
\end{tabular} \\
\hline & & & & \\
\hline $\begin{array}{l}\text { 17. SECURTY CLASSIFICATION } \\
\text { OF REPORT } \\
\text { Unclassified }\end{array}$ & $\begin{array}{l}\text { 18. SECURITY CLASSIFICATION } \\
\text { OF THIS PAGE } \\
\text { Unclassified }\end{array}$ & $\begin{array}{l}\text { 19. SECUAITY CLASSIFICA } \\
\text { OF ABSTRACT } \\
\text { Unclassified }\end{array}$ & ATION & 20. LIMITATION OF ABSTRACT \\
\hline
\end{tabular}

